\title{
EPIDEMIOLOGY OF MIDFACE FRACTURES IN RURAL SETUP IN SOUTH INDIA
}

\author{
A. Balasundaram 1 , K. Boopathi ${ }^{2}$
}

${ }_{1}^{1}$ Assistant Professor, Department of Plastic Surgery, Government Chengalpattu Medical College, Chengalpattu, Tamilnadu, India. 2Professor, Department of Plastic Surgery, Government Chengalpattu Medical College, Chengalpattu, Tamilnadu, India.

\section{BACKGROUND} ABSTRACT

The present modern fast-moving life paves way for an increase in number of motor vehicle accidents among the rural population of Tamilnadu, India. This has resulted in the midfacial fractures as one of the commonest fractures. Most of the studies pertaining to face trauma have been dealt in urban areas. But very little scientific literature is available for rural area population. Our institution is a tertiary care centre situated in rural area on the National Highway 32 and we receive more number of RTAs involving face. Aims and Objectives-

1. To study the prevalence of midfacial fractures in our population.

2. To analyse the data for various parameters (Age, sex, subtype, aetiology).

3. To investigate as to which subgroups are more vulnerable.

4. To suggest relevant remedial measures.

\section{MATERIALS AND METHODS}

This is a retrospective descriptive study of the patients who were admitted under the Department of Plastic Surgery in Chengalpattu Medical College with midfacial fractures between Jan 2017 and Dec 2017. Based on the medical records, prevalence, aetiology, age distribution, treatment and fracture types were evaluated.

\section{RESULTS}

Male patients far outnumbered the females and the commonest age group was 20 - 40. Zygoma fractures were the commonest, amongst patients who had isolated arch fractures and contributed 29\%. RTA was the commonest cause, with drunken driving without helmet being the most significant contributing factor.

\section{CONCLUSION}

Emphasis on road rules and strict implementation of the law to curb the menace of drunken driving can greatly help in reducing the morbidity and mortality associated with facial fractures.

\section{KEY WORDS}

Midface, RTA, Zygoma.

HOW TO CITE THIS ARTICLE: Balasundaram A, Boopathi K. Epidemiology of midface fractures in rural setup in South India. J. Evolution Med. Dent. Sci. 2018;7(45):4862-4864, DOI: 10.14260/jemds/2018/1083

\section{BACKGROUND}

Road Traffic Accidents (RTAs) are one of the leading causes of morbidity and mortality in India. Tamilnadu has the dubious distinction of the state with the highest number of RTAs ( $14.5 \%$ of the total accidents in India). $30.2 \%$ of all accidents are highway related. ${ }^{1}$ Our institution is a tertiary care referral centre located on National Highway 32 and we receive a lot of RTAs involving facial injuries. The main aim of this study was to analyse the patients with respect to age, aetiology, other contributing factors and types of fractures and to suggest the ways to prevent these fractures.

\section{MATERIALS AND METHODS}

A retrospective descriptive study of all the patients who were diagnosed to have midfacial fractures admitted consecutively in our institution between Jan 2017 and Dec 2017 were included in the study. A CT scan with 3D reconstruction was

'Financial or Other Competing Interest': None.

Submission 18-09-2018, Peer Review 17-10-2018,

Acceptance 25-10-2018, Published 05-11-2018.

Corresponding Author:

Dr. K. Boopathi,

30. D. Hospital Road,

Kanchipuram-631502, Tamilnadu, India.

E-mail:drkbpathi@gmail.com

DOI: $10.14260 /$ jemds $/ 2018 / 1083$

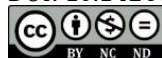

done to plan the appropriate treatment for the patients. Patients who expired after admission and those with head injuries requiring Neurosurgical intervention were excluded from the study. Data including age, gender, mode of injury, aetiology, anatomical fracture site, alcohol abuse, helmet usage and treatment given were recorded. The aetiology was categorised into 3 categories.(1) RTAs including driver, pillion rider and pedestrians. Of the people in RTAs involving two wheelers, data regarding helmet and alcohol usage at the time of injury was recorded with assault and self-fall. The fractures were assessed and recorded as one of the following regions- Nasal, Le Fort 1, Le Fort 2, Dentoalveolar and Zygomatic. Zygoma fractures were further subclassified as infraorbital, infraorbital and lateral wall, ZMC, arch fractures and infraorbital with arch fractures.

\section{RESULTS}

A total of 94 patients and 96 midfacial fractures were analysed. Male patients far outnumbered the females with a ratio of 14: 1. Commonest age group was 21 - 30 years (35 patients) and $70 \%$ were between 20 and 40 years of age. 


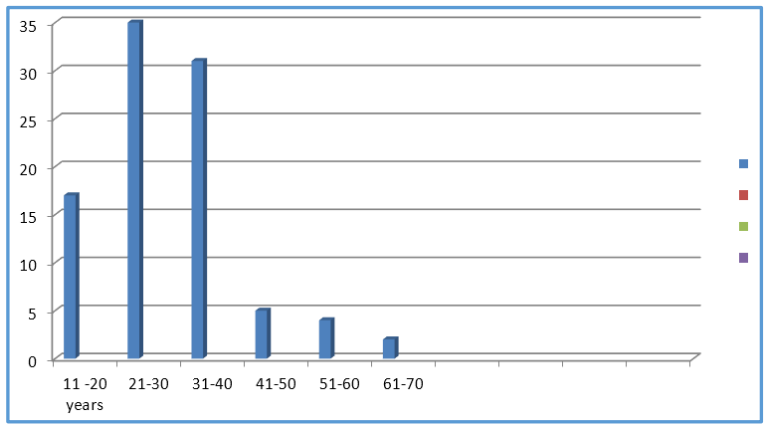

\section{Age Distribution}

Commonest aetiology with 80 patients was due to RTAs. The next was assault in 10 patients. Self-fall contributed by 4 patients. Amongst RTAs, 75 patients were on a two-wheeler at the time of accident (58 drivers and 17 pillions). Of the 75 patients, 73 did not wear a helmet at the time of injury. Amongst the 58 patients who were driving a two-wheeler, 50 patients were under the influence of alcohol at the time of injury.

The commonest fractures were those involving the zygomatic complex (58 patients). There was no preference for any side with both left and right almost the same. 28 patients had right sided fracture involving the zygoma and 29 patients had left sided fracture. One patient had a bilateral Zygomatic complex involvement. The next commonest site with 22 patients was nasal bone fractures. There were 7 associated fractures of the face ( 2 frontal and 5 mandible).

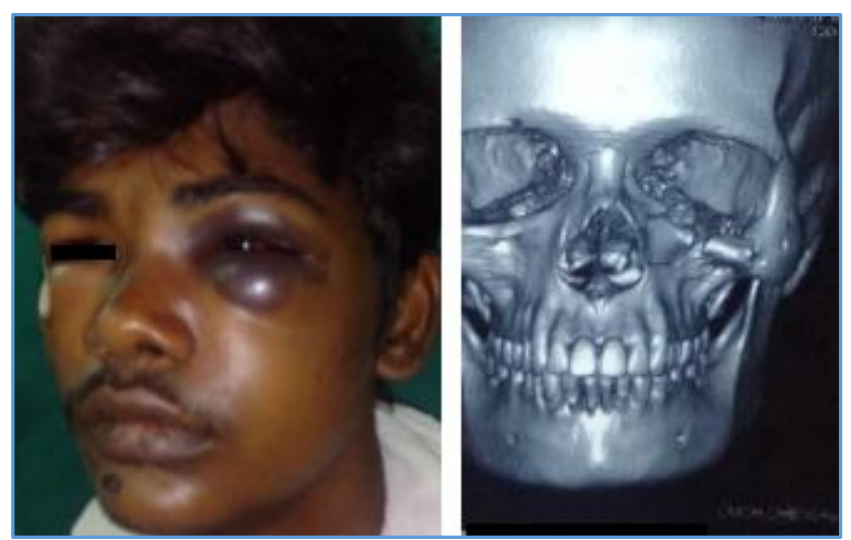

Picture I. Inferior Orbital Wall

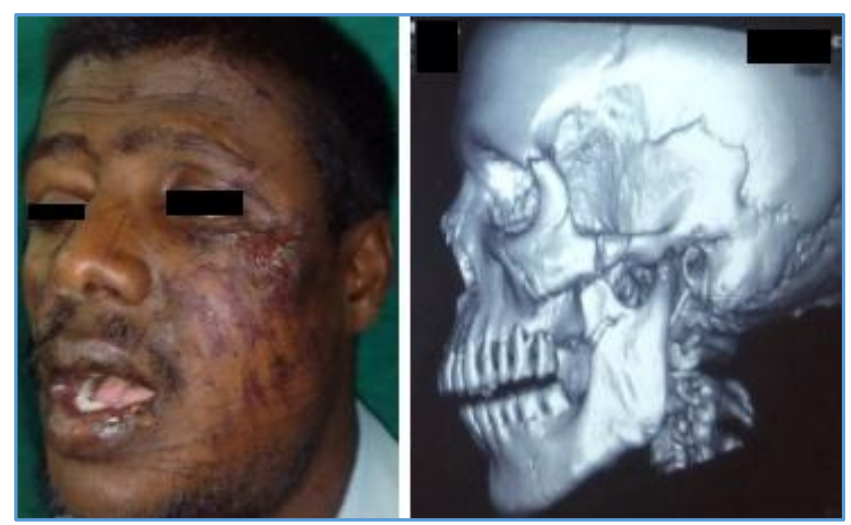

Picture II. ZMC with Coronoid

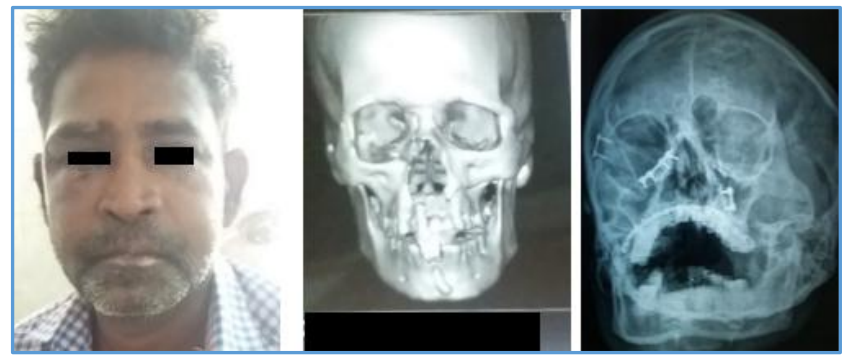

Picture III. Infraorbital Fractures with ORIF

\begin{tabular}{|c|c|c|}
\hline Type & Number & Percentage \\
\hline Le Fort I & 4 & $4.16 \%$ \\
\hline Le Fort II & 6 & $6.25 \%$ \\
\hline Infraorbital Zygoma & 14 & $14.6 \%$ \\
\hline Infraorbital and lateral wall & 8 & $8.33 \%$ \\
\hline ZMC (Tripod fracture) & 16 & $16.66 \%$ \\
\hline Zygomatic Arch & 17 & $17.8 \%$ \\
\hline Arch and infraorbital wall & 3 & $3.12 \%$ \\
\hline Nasal bone & 22 & $22.92 \%$ \\
\hline Dentoalveolar & 6 & $6.25 \%$ \\
\hline Total & 96 & \\
\hline Midface Fracture Subtypes \\
\hline
\end{tabular}
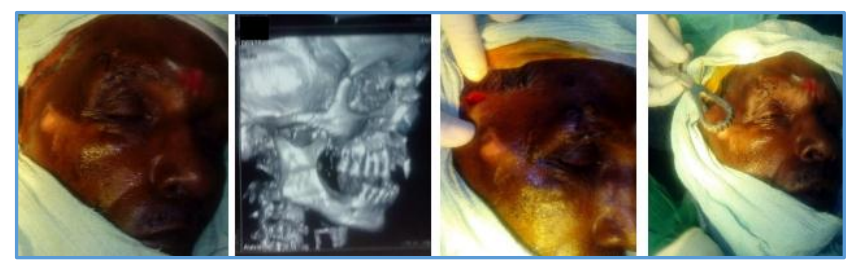

Picture IV. Zygomatic Arch - Closed Reduction
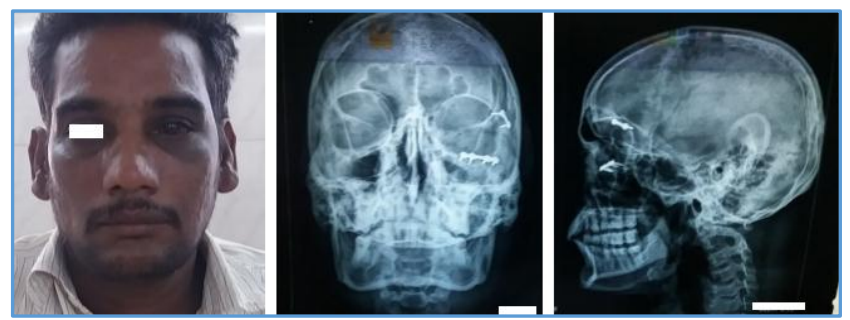

Picture V. Infraorbital and Zygoma \# - ORIF

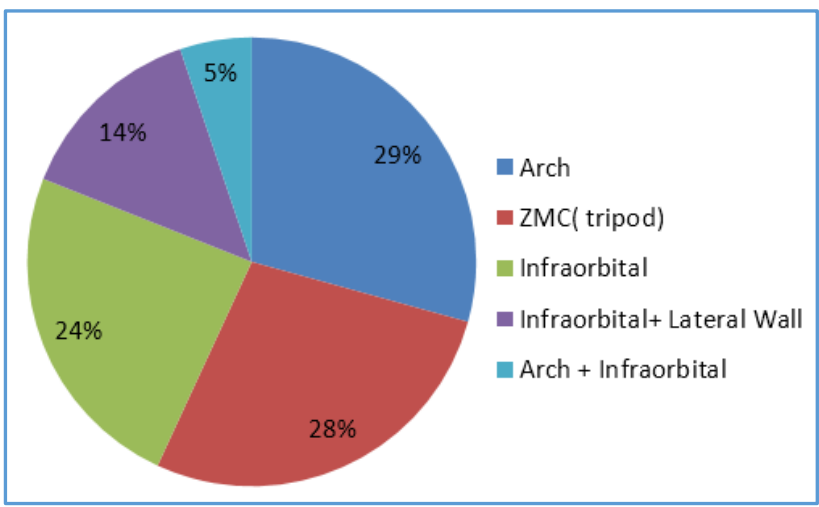

Zygoma Fracture

All the isolated Zygomatic arch fractures were treated by elevation through Gillies approach. In one patient, elevation alone was not sufficient as the fracture was unstable and required an ORIF. The dentoalveolar fractures were primarily treated with MMF. 


\begin{tabular}{|c|c|c|}
\hline Treatment & No. of Patients & Percentage \% \\
\hline MMF & 8 & 8.33 \\
\hline Elevation & 16 & 16.66 \\
\hline ORIF & 50 & 52.08 \\
\hline $\begin{array}{c}\text { Closed reduction } \\
\text { and moulding }\end{array}$ & 22 & 22.91 \\
\hline Total & $\mathbf{9 6}$ & \\
\hline
\end{tabular}

\section{DISCUSSION}

There is a very high association between maxillofacial trauma and road traffic accidents, as proved by many studies. ${ }^{2}$ In the current study, $70 \%$ of the patients were in the $20-40$ age group. This is comparable to work done by others. ${ }^{3}$ In the rural parts of the country, two wheelers are the most commonly used mode of transport. The age group from 20-40 represents the active workforce who are more vulnerable to injury.

The male predominance has been reported in many studies 4 and could partly be attributed to the fact that more women in the rural regions are homemakers and they do not drive a motorised vehicle due to socioeconomic and cultural constraints. The male-to-female ratio of 14: 1 in our study is more than the 9: 1 reported by Singh V et al. ${ }^{5}$

Midfacial fractures were caused due to RTAs in 80 patients (85\%). This has also been proved in other studies to be the commonest cause of facial injuries.6,7 Amongst RTAs, two wheelers were the vehicles of transport in 75 patients. A staggering $97 \%$ of the patients who were travelling in a twowheeler did not wear helmet at the time of injury and $86 \%$ of the patients who were driving were under the influence of alcohol. Studies reported from nearby cities (Chennai) only showed $41.6 \%$ of the patients were influenced by alcohol. 8 Prabhu et $\mathrm{al}^{9}$ reported that even as alcohol consumption is decreasing in some developed countries it is on the rise in developing nations, particularly among those aged 21 to 35 years. The high incidence of alcohol abuse could be due to the lower socioeconomic status of the people and also insufficient law enforcement.

Although, many classification systems exist for classifying midfacial fractures (Le Fort, Rowe and Williams), for ordinary practical purposes and treatment planning a simpler classification as follows is adopted. ${ }^{10}$

1. Dentoalveolar fractures.

2. Zygomatic complex fractures.

3. Nasal complex fractures.

4. Le Fort I.

5. Le Fort II.

6. Le Fort III.

In the current study, it was found that $61 \%$ of the fractures involved the Zygomatic complex. 23\% were nasal bone fractures. A comprehensive study of 629 midface fractures by Rowe and Killey in 1968 showed a similar proportion of Zygoma fractures. A study by Gopalakrishna et al showed $16 \%$ of the fractures to be involving the nasal bone. ${ }^{11}$ We found no difference as far as the side involved by fracture with equal representation for both right and left. However, certain studies report more fractures on the right side. ${ }^{8}$ This has been explained by the right hand dominance of the patients and subsequent fall on that side. As alcohol abuse amongst our study population was very high, the dominant hand did not play a major role in our patients.
The patients with isolated Zygoma arch fractures were treated with closed elevation. Only one patient required ORIF, as the fracture was unstable. Dentoalveolar fractures were primarily treated with MMF. All other patients were treated with ORIF. $1.5 \mathrm{~mm}$ plates were used and fixed with screws of appropriate length.

\section{CONCLUSION}

Zygoma fractures were the commonest, amongst patients who had isolated arch fractures. A significant proportion of these patients were under the influence of alcohol without wearing a helmet. Strict law enforcement to deter these careless acts is urgently required. Proper education at school and college level, compulsory educational sessions during issuing/ renewal of driving license will serve the purpose of spreading awareness amongst the population.

\section{REFERENCES}

[1] Ruikar M. National statistics of road traffic accidents in India. J Orthop Traumatol \& Rehabil 2013;6(1):1-6.

[2] Chalya PL, Mchembe M, Mabula JB, et al. Etiological spectrum, injury characteristics and treatment outcome of maxillofacial injuries in a Tanzanian teaching hospital. J Trauma Manag Outcomes 2011;5:7-13.

[3] Bataineh AB. Etiology and incidence of maxillofacial fractures in the north of Jordan. Oral Surg Oral Med Oral Pathol Oral Radiol Endod 1998;86(1):31-5.

[4] Kapoor P, Kalra N. A retrospective analysis of maxillofacial injuries in patients reporting to a tertiary care hospital in East Delhi. Int J Crit Illn Inj Sci 2012;2(1):6-10.

[5] Singh V, Malkunje L, Mohammad S, et al. The maxillofacial injuries: a study. National J Maxillofacial Surgery 2012;3(2):166-71.

[6] Ozkaya 0, Turgut G, Kayali MU, et al. A retrospective study on the epidemiology and treatment of maxillofacial fractures. Turkish J Trauma \& Emergency Surgery: Ulus Travma Acil Cerrahi Derg 2009;15(3):262-6.

[7] Subhasraj K, Nandakumar N, Ravindran C. Review of maxillofacial injuries in Chennai, India: a study of 2748 cases. Br J Oral Maxillofac Surg 2007;45(8):637-9.

[8] Singaram M, Vijayabala SG, Udhayakumar RK. Prevalence, pattern, etiology and management of maxillofacial trauma in a developing country: a retrospective study. J Korean Assoc Oral Maxillofac Surg 2016;42(4):174-81.

[9] Prabhu P, Srinivas R, Vishwanathan K, et al. Factors influencing alcohol and tobacco addiction among patients attending a de-addiction Centre, South India. J Int Soc Prev Community Dent 2014;4(2):103-7.

[10] Banks P. Killey's fractures of the middle third of the facial skeleton. John Wright Publisher 1988.

[11] Gopalakrishna G, Peek-Asa C, Kraus JF. Epidemiologic features of facial injuries among motorcyclists. Ann Emerg Med 1998;32(4):425-30. 